\title{
Pemantauan Emisi dengan Continuous Emission Monitoring System (CEMS) dalam Pemanfaatan Minyak Pelumas Bekas Sebagai Subtitusi Bahan Bakar pada Produksi Kapur Tohor
}

\author{
Arif Susanto1,2,3, Purwanto Purwanto ${ }^{1,4}$, Edi K. Putro ${ }^{3}$, Wiliam E. Yochu³, Uli Amrina3,5, \\ dan Fajrul Falakh6
}

${ }^{1}$ Green Technology Research Center, Program Doktor Ilmu Lingkungan, Sekolah Pascasarjana Universitas Diponegoro, Semarang 50241; e-mail: arifssnt@yahoo.com

${ }^{2}$ Program Studi Teknik Lingkungan, Fakultas Teknik Sipil dan Perencanaan, Universitas Kebangsaan Republik Indonesia, Bandung 40268

${ }^{3}$ Departemen Safety Health \& Environmental, Divisi Concentrating PT Freeport Indonesia, Tembagapura 99960

${ }^{4}$ Program Studi Teknik Kimia, Fakultas Teknik, Universitas Diponegoro, Semarang 50275

5Program Studi Teknik Lingkungan, Fakultas Teknik, Universitas Indonesia, Depok 16424

${ }^{6}$ Program Studi Biologi, Fakultas Sains dan Teknologi, Universitas Islam Negeri Walisongo, Semarang 50185

\begin{abstract}
ABSTRAK
Minyak pelumas bekas atau biasa disebut used oils yang berasal dari minyak pelumas bekas hidrolik, mesin-mesin, gear, lubrikasi, insulasi, heat transmission, grit chambers, oil water separator dan atau campurannya termasuk kedalam limbah bahan berbahaya dan beracun (B3) dari kegiatan industri. Limbah B3 (LB3) tersebut memiliki simbol mudah terbakar dan berkategori bahaya 1. Used oils tersebut dapat dimanfaatkan sebagai substitusi sumber energi dengan tetap mempertimbangkan ketersediaan teknologi maupun baku mutu lingkungan hidup agar tidak menimbulkan pencemaran udara. Tujuan penelitian ini yaitu untuk mengevaluasi sistem pemantauan dan pengendalian pencemaran udara pada pemanfaatan limbah minyak pelumas bekas, yaitu sebagai subtitusi bahan bakar pada produksi kapur tohor apakah telah sesuai dengan persyaratan peraturan dan perundangan Republik Indonesia (RI). Metode penelitian menggunakan triangulasi teknik dengan cara mengumpulkan data yang berbeda-beda agar diperoleh data dari sumber yang sama. Sumber data dan lokasi penelitian dilakukan di unit produksi kapur tohor yang berada di daerah tambang terbuka Grasberg PT Freeport Indonesia (PTFI). Hasil pemantauan emisi pemanfaatan used oils dengan minyak solar dengan continuous emission monitoring system (CEMS) telah memenuhi persyaratan dan peraturan perundangan RI. Metode pengambilan sampel CEMS yang diterapkan yaitu in stack dilution extractive untuk memantau parameter partikulat dan gas. Pengendalian pencemaran udara lainnya dilakukan dengan sejumlah tindakan dan pengelolaan lainnya. Upaya pengelolaan tersebut dapat berupa kegiatan pemeliharaan dan penggantian rutin unit filter bag pada baghouse, pemeliharaan induced draft (ID) fan, pengendalian dan pematauan tekanan udara, dan persentase debit campuran antara used oils dan minyak solar.
\end{abstract}

Kata kunci: CEMS, emisi, minyak pelumas bekas, pemanfaatan limbah B3, subtitusi bahan bakar, kapur tohor.

\begin{abstract}
Used oils derived from used hydraulic oil, machinery, gear, lubrication, insulation, heat transmission, grti chambers, oil water separator and their mixtures are implicated as hazardous waste (B3) generated from industrial activities. Also, these hazardous waste (LB3) has a flammable symbol and are categorized as hazard 1. The used oils can be utilized as a substitute for energy sources while still considering the availability of technology and environmental quality standards in order to prevent air pollution. This process would also include inhibiting the generation of greenhouse gases (GHG) and negative impact on human health as well as the environment. Therefore, the purpose of this study was to evaluate the monitoring and control system of air pollution in order to determine wether the utilization of used oils as a fuel substitute for quicklime production is in accordance with the requirements of Indonesian regulations and laws. The research method made use of technical triangulation by collecting different data in order to ensure obtainment from the same source. In addition, this research and the collection process were carried out in the quicklime production unit located in the PT Freeport Indonesia (PTFI), Grasberg open pit mining area. The results of observing emissions released from the utilization of used oils and diesel fuel with a continuous emission monitoring system (CEMS) have fulfilled the requirements of Indonesia legal policies. The CEMS sampling method applied was in stack dilution extractive, in order to monitor particulate and gas parameters. Other types of air pollution control are carried out with a number of additional maintenance and management. Meanwhile, the efforts employed in the management process can be in the form of routine maintenance and replacement of filter bag units in the baghouse (a pollution control device). Furthermore, this can also include the servicing of induced draft (ID) fans, control and monitoring of air pressure, as well as the percentage of mixed discharge between used oils and diesel fuel.
\end{abstract}

Keywords: CEMS, emission, used oils, hazardous waste utilization, fuel subtitution, lime.

Citation: Susanto, A., Purwanto, P., Putro, E,K., Yochu, W.E., Amrina, U. dan Falakh, F. (2020). Pemantauan Emisi dengan Continuous Emission Monitoring System (CEMS) dalam Pemanfaatan Minyak Pelumas Bekas sebagai Subtitusi Bahan Bakar pada Produksi Kapur Tohor. Jurnal Ilmu Lingkungan, 18(2), 392-400, doi:10.14710/jil.18.2.392-400 
Susanto, A., Purwanto, P., Putro, E,K., Yochu, W.E., Amrina, U. dan Falakh, F. (2020). Pemantauan Emisi dengan Continuous Emission Monitoring System (CEMS) dalam Pemanfaatan Minyak Pelumas Bekas sebagai Subtitusi Bahan Bakar pada Produksi Kapur Tohor. Jurnal Ilmu Lingkungan, 18(2), 392-400, doi:10.14710/jil.18.2.392-400

\section{Pendahuluan}

Sejalan dengan kemajuan teknologi dan arus pesat pengembangan berbagai industri maka dampak kegiatan industri tersebut dapat berbanding terbalik dengan kondisi lingkungan, diantaranya yaitu peningkatan polusi dan semakin banyak akumulasi timbulan limbah bahan berbahaya dan beracun (LB3). Dampak yang ditimbulkan oleh LB3 yang dibuang langsung ke lingkungan berjumlah besar dan dapat bersifat akumulatif, yang dapat berdampak berantai mengikuti proses pengangkutan (sirkulasi) bahan dan jaring-jaring rantai makanan. Potensi akumulasi timbulan LB3 tersebut cukup signifikan, sehingga diperlukan manajemen pengelolaan yang tepat dan berkelanjutan (Susanto dkk, 2016).

Konsep pengelolaan LB3 telah mengalami perubahan dari tindakan pengolahan yang bersifat penanggulangan terhadap limbah yang keluar dari proses produksi (end of pipe treatment) menjadi pencegahan (in front of the pipe). Tindakan pencegahan tersebut meliputi reduksi pada sumber (reduction), pemakaian kembali (reuse), dan daur ulang (recycle), serta minimalisasi limbah yaitu berupa pengurangan volume, pengurangan konsentrasi, penurunan toksisitas, dan penurunan tingkat bahaya limbah yang berasal dari proses produksi. Hal tersebut dilakukan dengan jalan reduksi pada sumbernya dan/atau pemanfaatan limbah (ICMM, 2020).

International Council on Mining and Metals (ICMM) telah menyusun sepuluh prinsip pengolahan pertambangan berkelanjutan. Sepuluh prinsip pengelolaan pertambangan berkelanjutan tersebut menyebutkan bahwa kegiatan pertambangan harus memfasilitasi dan mendorong desain produksi, penggunaan kembali (reuse), daur ulang (recycling) dan pembuangan produk secara bertanggung jawab. Salah satu LB3 yang perlu dikelola dengan baik adalah minyak pelumas bekas (used oils) yang timbulannya meningkat cukup signifikan, akibat dari kegiatan perawatan permesinan, perbengkelan dan lainlainnya (PTFI, 2019).

Used oils tergolong dalam LB3 sesuai dengan Peraturan Pemerintah Republik Indonesia Nomor 101 tahun 2014 tentang Pengelolaan Limbah Bahan Berbahaya dan Beracun (PI, 2014). Used oils tersebut memiliki simbol mudah terbakar (KLH, 2013) dengan kode limbah A340-2 dan berkategori bahaya 1 (KLHK, 2015; KLHK, 2020a). Termasuk kedalam minyak pelumas bekas atau used oils antara lain yaitu minyak pelumas bekas hidrolik, mesin, gear, lubrikasi, insulasi, heat transmission, grit chambers, separator dan/atau campurannya. Used oils tersebut dapat dimanfaatkan sebagai substitusi sumber energi sesuai Pasal 54 ayat (1) huruf c yaitu dilakukan dengan mempertimbangkan ketersediaan teknologi dan baku mutu (standar) lingkungan hidup (PI, 2014). Contoh pemanfaatan used oils sebagai substitusi sumber energi antara lain berupa pemanfaatan oil sludge, oil sloop dan oli bekas yang dimanfaatkan sebagai bahan bakar alternatif pada industri semen (KLHK, 2015).

Used oils menjadi perhatian utama bagi PTFI. Akumulasinya meningkat sejalan dengan peningkatan kapasitas produksi, penambahan permesinan dan pembukaan proyek tambang baru. Rerata jumlah timbulan minyak pelumas bekas sebanyak lebih dari 1 juta gallon per bulan. PTFI melakukan berbagai upaya dalam untuk mengurangi jumlah akumulasi tersebut yaitu dengan tidak mengirimkannya ke pihak ketiga, namun digunakan sebagai substitusi sumber energi dengan mengacu kepada tata cara perizinan pengelolaan LB3 (KLH, 2009) dan izin lingkungan (PI, 2012). Hal tersebut dilakukan juga sebagai implementasi Undang Undang (UU) RI Nomor 32 tahun 2009 tentang Perlindungan dan Pengelolaan Lingkungan Hidup (PPLH, 2009). Selain itu, dilakukan untuk mengurangi biaya operasional dalam proses pengiriman LB3 tersebut kepada pihak ketiga, dapat menghemat energi dalam penggunaan bahan bakar, serta ditujukan untuk mencegah insiden tumpahan (spill) saat transportasi dan mengurangi jejak emisi karbon (carbon foot print) (PTFI, 2019).

Pemanfaatan used oils berpotensi menimbulkan pencemaran udara (PU). Oleh karena itu diperlukan pengendalian terhadap emisi gas yang dibuang ke udara. Dampak dari pencemaran udara yaitu timbulnya gas rumah kaca (GRK) (USEPA, 2020a) dan dapat berpengaruh terhadap kesehatan (WHO, 2020), sehingga pengendalian pencemaran udara (PPU) wajib dilaksanakan oleh industri yang memanfaatkan LB3 tersebut (KLH, 2008). Upaya PPU ini yaitu pemantauan kadar dan kandungan zat pencemar (emisi) yang ditimbulkan dari proses produksi kapur tohor yang memanfaatkan used oils sebagai substitusi bahan bakar memenuhi persyaratan baku mutu yang telah ditetapkan oleh Pemerintah RI (KLHK, 2015). Metode pemantauan emisi tersebut yaitu dengan penggunaan continuous emission monitoring system (CEMS), selain pemantauan manual (USEPA, 2020b). Tujuan penelitian ini yaitu untuk mengevaluasi sistem pemantauan pengendalian pencemaran udara dalam pemanfaatan limbah minyak pelumas bekas sebagai subtitusi bahan bakar pada produksi kapur tohor apakah telah sesuai dengan peraturan perundangan RI.

\section{Metode}

Penelitian ini menggunakan metode triangulasi teknik. Metode ini yaitu menggunakan teknik pengumpulan data yang berbeda-beda untuk memperoleh data dari sumber yang sama. Penggunaan observasi partisipatif dan kajian dokumentasi dilakukan secara serentak (Sugiyono, 2011). Obervasi dan kajian dokumentasi tersebut dilakukan pada seluruh rangkaian proses unit pengolahan kapur tohor pada pabrik kapur. Diagram alir pengolahan tersebut digambarkan pada gambar 1 di bawah ini. Wawancara dilakukan kepada petugas yang bekerja pada setiap proses untuk memperoleh 
informasi mendalam mengenai hal penting pada setiap proses produksinya.

Sumber data pada penelitian ini yaitu unit produksi pabrik pengolahan kapur tohor. Lokasi penelitian dilakukan di pabrik kapur Mahaka yang berlokasi di daerah tambang terbuka Grasberg PT Freeport Indonesia. Sumber data menggunakan data primer dan sekunder yang dikumpulkan yaitu selama Januari sampai Desember tahun 2019. Data primer diperoleh di beberapa titik lokasi dari proses produksi kapur tohor yaitu pada oil water separator, proses pengumpulan used oils di tanki penyimpanan, unit proses mixing, unit pengendalian debu dan cerobong.

\section{Hasil dan Pembahasan}

\subsection{Gambaran Umum}

PTFI adalah perusahaan yang bergerak di bidang pertambangan Tembaga dan Emas dan telah beroperasi sejak tahun 1972 di Kabupaten Mimika, Provinsi Papua. Kegiatan yang berlangsung didasarkan kepada Izin Usaha Pertambangan Khusus Operasi Produksi (IUPKOP) yang diterbitkan oleh Menteri Energi dan Sumber Daya Mineral (ESDM) Nomor 2053 K/30/MEM/2018 tanggal 21 Desember 2018. PTFI memanfaatkan batuan gamping yang cukup melimpah di daerah tambang terbuka Grasberg dan bubur kapur tohor yang diproduksi dari batu gamping tersebut pada pabrik pengolahan kapur. Hasil produksi kapur tersebut digunakan dalam pencegahan dan penetralan air asam batuan dan kegiatan produksi.

Pabrik pengolahan kapur Mahaka tersebut dibangun pada tahun 1996-1997, dengan kapasitas produksi maksimum 400 metrik ton $\mathrm{CaO}$ per hari. Produksi kapur disesuaikan dengan kebutuhan operasi pabrik pengolahan bijih dan penggunaan lain seperti pencampur batuan penutup di daerah tambang (PTFI, 2019).

Pemanfaatan used oils sebagai substitusi sumber energi oleh PTFI dilakukan sesuai dengan pasal 54 ayat 3 yaitu ketentuan lebih lanjut mengenai rincian masing-masing. Pemanfaatan LB3 sebagaimana dimaksud pada ayat (1) diatur dalam Peraturan Menteri (PI, 2014). Hal ini tertuang dalam Keputusan Menteri Lingkungan Hidup dan Kehutanan (KLHK) Nomor 07.37.06 Tahun 2015 tentang Izin Pemanfaatan Limbah Berbahaya dan Beracun berupa Minyak Pelumas Bekas pada Unit Pembakaran Pabrik Kapur Mahaka PTFI (KLHK, 2015; PTFI, 2019).

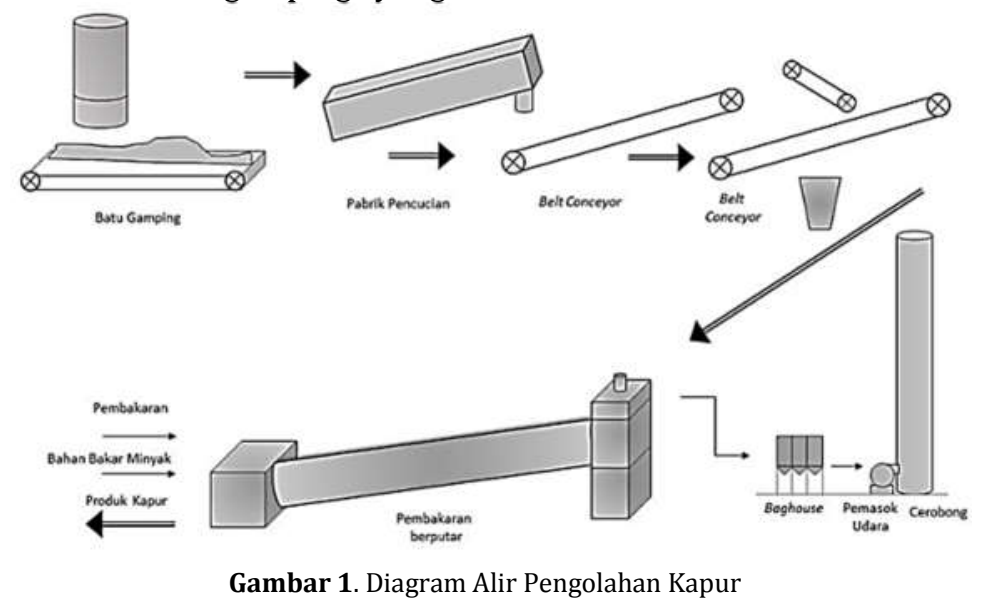

\subsection{Operasi Produksi Kapur Tohor}

Pabrik kapur terdiri dari tanur putar (rotary kiln) dengan desain produksi maksimal 400 ton kapur per hari. Lime dehydrator digunakan untuk mengubah batu kapur kedalam bentuk hidroksida. Dalam proses produksi kapur tohor seperti digambarkan pada gambar 1, pemanfaatan used oils dilakukan dengan beberapa tahapan, yaitu tahapan pertama yang diawali oleh pemisahan used oils dari pengotor (kontaminan). Kontaminan tersebut dapat berupa pasir, sampah, maupun pengotor lain. Selanjutnya dilakukan proses pengurangan kandungan air (water content). Used oils tersebut kemudian ditampung dalam tanki penyimpanan untuk kemudian dipompakan ke sistem pencampur dengan menggunakan static mixer secara bersamaan dengan minyak solar dalam proses pencampuran (mixing).

Tahapan lanjut pada proses mixing adalah proses pemananasan awal (preheating). Proses awal tersebut dilakukan pada unit preheater digambarkan seperti pada gambar 2. Pada tahap ini diharapkan terjadi proses pencampuran sempurna (blending) antara used oils dengan minyak solar sehingga didapatkan bahan bakar yang homogen.

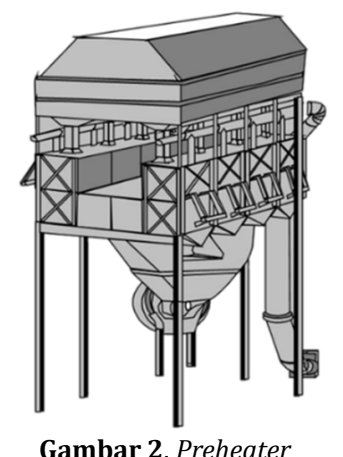

Rasio perbandingan komposisi antara minyak pelumas bekas dan minyak solar yaitu tidak melebihi $80 \%$ dari total kebutuhan bahan bakar sesuai 
persyaratan perizinan KLHK Nomor 07.37.06 Tahun 2015. Pemanasan awal ini berlangsung pada temperatur $46^{\circ}$ sampai $70^{\circ}$ Celcius. Hasil pencampuran tersebut kemudian diumpankan ke ruang tanur bakar (rotary kiln) seperti yang digambarkan pada gambar 3 untuk kemudian dialirkan melalui sebuah nozzle, sehingga campuran minyak yang telah homogen tersebut akan teratomisasi pada ruang bakar yang memiliki temperatur pembakaran pada $850^{\circ}$ sampai $960^{\circ}$ Celcius.

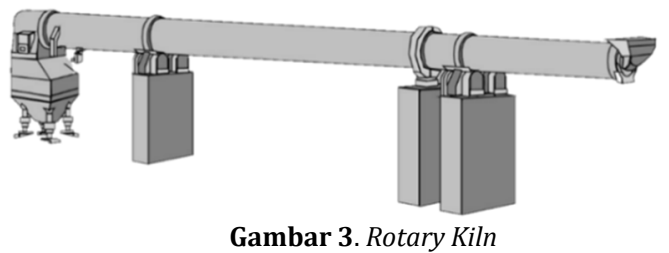

Pengendalian debu yang terbentuk dari proses produksi kapur tohor ini dilakukan pada unit filter bag house yang terdiri dari empat bagian kompartemen. Setiap kompartemen berisi 336 kantong filter. Material filter bag tersebut menggunakan bahan Huyglass dan tahan terhadap suhu hingga $260^{\circ} \mathrm{C}$. Udara dari rotary kiln dihisap kedalam bag house menggunakan Induced Draft (ID) Fan melalui menyaring dan sisa partikel debu di permukaan bag filter. Partikel debu yang terhisap oleh ID fan tersebut kemudian dikumpulkan di dust bin (gambar 4).

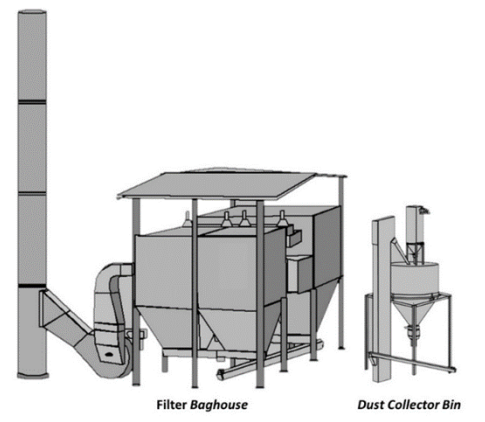

Gambar 4. Filter Bag House dan Dust Bin
Dimensi cerobong pada pabrik pengolahan kapur ini memiliki tinggi 29,6 meter dan dengan diameter 2,5 meter. Cerobong ini memiliki empat port untuk pengambilan sampel pada posisi sudut kanan dipasang dengan ukuran diameter masing-masing 10 cm dan pada level 20,4 meter dari pangkalan dan 1,2 meter pada platform di atas (gambar 5). Cerobong tersebut dilengkapi dengan tangga baja dan pengaman perangkat pendakian, dengan suhu ambien sekitar $130^{\circ}$ Celcius. Teknis PPU tersebut telah memenuhi persyaratan (BAPEDAL, 1996) dan agar memenuhi baku mutu emisi sumber emisi tidak bergerak (KLH, 2014) dan persyaratan perijinannya (KLHK, 2015).

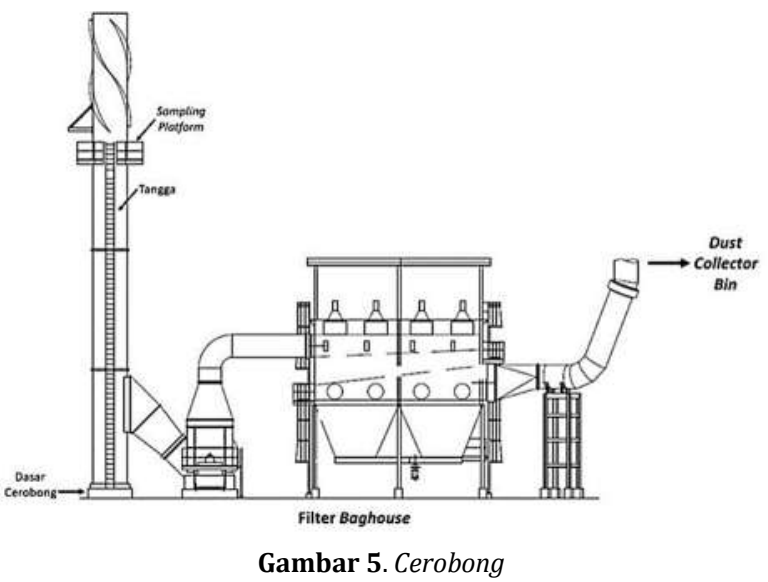

\subsection{Karakteristik dan Pengelolaan Used Oils}

Pengelolaan used oils di PTFI dilakukan secara terintegrasi dimulai dari proses pengumpulan pada setiap proses produksi, kegiatan perawatan (maintenance), perbengkelan dan lainnya. Gambar 6 menggambarkan urutan proses dalam pengelolaan used oils yang dimulai dari proses pengelolaan dari lokasi-lokasi pengumpulan sementara yang sesuai dengan persyaratan teknis penyimpanan dan pengumpulan LB3 (KLHK, 2020b).

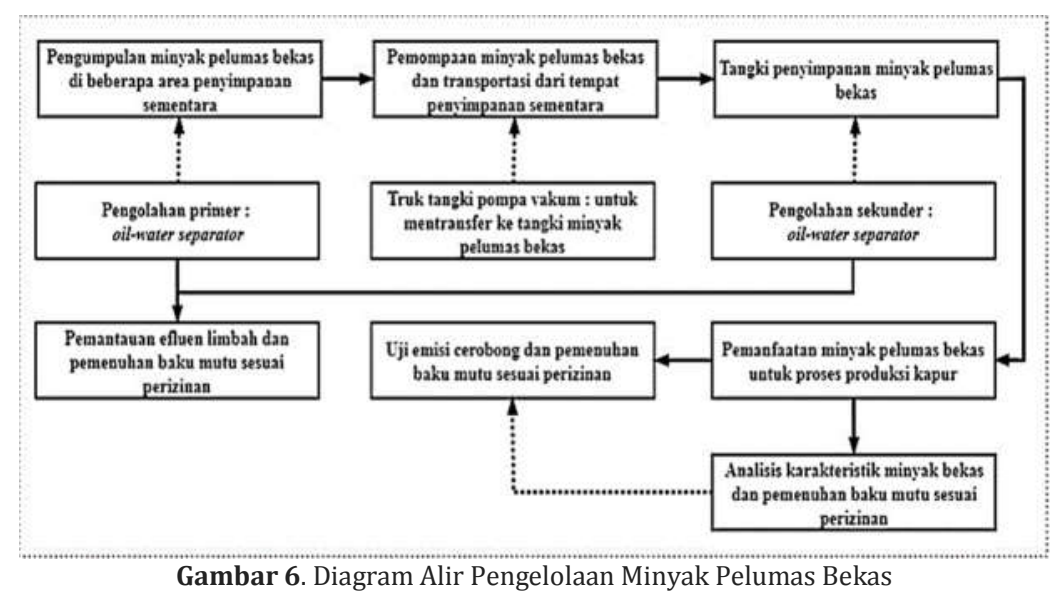

Dari lokasi pengumpulan sementara tersebut kemudian dilanjutkan dengan pengumpulan secara terpusat di transfer point untuk dilakukan pengolahan primer (BAPEDAL, 1995), yaitu pemisahan minyak dan air pada unit oil-water separator (OWS) (LópezVazquez and Fall, 2004) seperti yang digambarkan 
pada gambar 7. Minyak pelumas bekas yang sudah terpisah dengan kontaminan, seperti air, lumpur maupun pengotor lain kemudian dikumpulkan pada tanki penyimpanan lebih besar untuk proses produksi kapur. Used oils yang telah terpisah dengan kontaminan, khususnya dengan air yang merupakan kontaminan terbesar maka dilakukan analisis karakteristik agar dapat memenuhi persyaratan kualitas sesuai perizinan (KLHK, 2015).

Tabel 1. Baku Mutu dan Hasil Pengujian Used Oils

\begin{tabular}{|c|c|c|c|c|}
\hline Parameter & Satuan & Metode Analisis & Baku Mutu & Hasil Pengujian \\
\hline Arsen (As) & ppm & Inductively Coupled Plasma & 5 & $0,01-0,1$ \\
\hline Kadmium (Cd) & ppm & Inductively Coupled Plasma & 2 & $<0.01$ \\
\hline Kromium (Cr) & ppm & Inductively Coupled Plasma & 10 & $0,32-0,34$ \\
\hline Timbal (Pb) & ppm & Inductively Coupled Plasma & 100 & $0,09-0.93$ \\
\hline Flash Point* & ${ }^{\circ} \mathrm{C}$ & ASTM D-93 & 37,78 & $104-162$ \\
\hline Heating Value* & $\mathrm{Kkal} / \mathrm{kg}$ & ASTM D-240 & 2500 & $10.200-10.500$ \\
\hline Kandungan Air & $\%$ & ASTM D-95 & 15 & $0,05-0,5$ \\
\hline Total Organic Halogens (TOX) & $\mathrm{mg} / \mathrm{kg}$ & ASTM D-9076 & 4000 & $64-374$ \\
\hline
\end{tabular}

*nilai minimum

Sumber data diolah dari Keputusan Menteri Lingkungan Hidup dan Kehutanan Nomor 07.37.06 Tahun 2015

Used oils yang berada di transfer point dilakukan drain terlebih dahulu, sehingga kadar air dapat berkurang sebelum dilakukan pemompaan. Persyaratan kualitas used oils meliputi beberapa parameter penting, seperti kadar air, titik bakar, nilai energi dan kontaminan logam berat lain, seperti yang tertera pada tabel 1 di atas.

Hasil pengujian karakteristik used oils menunjukkan bahwa nilai kadar dari paremeter yang ditetapkan memenuhi perizinan KLHK Nomor 07.37.06 Tahun 2015. Nilai hasil pegujian kandungan parameter dari kontaminasi Arsen (As), Cadmium (Cd), Chromium (Cr) dan timbal (Pb) sangat rendah dibandingkan dengan baku mutu. Nilai parmeter titik nyala (flash point) yaitu suhu terendahused oils mengeluarkan uap yang cukup untuk membentuk campuran dengan udara yang terbakar sebesar 104 sampai $162^{\circ}$ Celcius.

Nilai titik nyala tersebut memenuhi persyaratan dan sesuai dengan spesifikasi preheater dalam proses pencampuran dengan minyak solar, sehingga tidak berpotensi terjadi pembakaran saat proses mixing. Nilai kalor (heating value) yaitu nilai panas yang dihasilkan dari pembakaran sempurna used oils tersebut yaitu 10.200 sampai $10.500 \mathrm{Kkal} / \mathrm{kg}$ atau sebesar 4 (empat) kali lipat nilai kalori minimum baku mutu yaitu $2500 \mathrm{Kkal} / \mathrm{kg}$. Sehingga secara umum limbah B3 tersebut dapat memberikan nilai kalori yang tinggi.

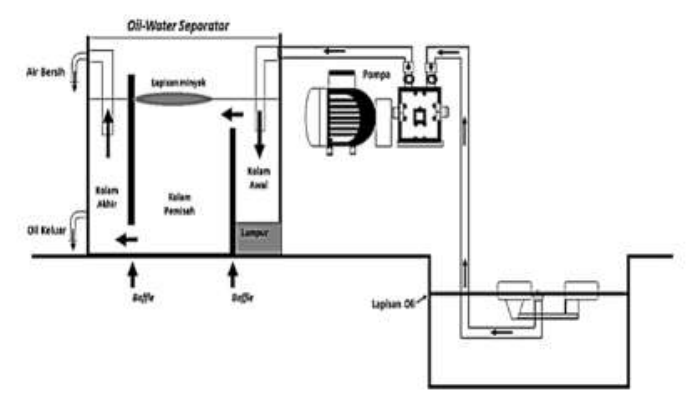

Gambar 7. Oil-water Separator

\subsection{Sistem Pemantauan Emisi Kontinu (CEMS)}

Pemantauan emisi bertujuan untuk memastikan bahwa emisi yang dihasilkan (KLH, 2008) dari proses pembakaran batu kapur menggunakan used oils sebagai campuran bahan bakar tidak melampaui baku mutu yang ditetapkan oleh Pemerintah RI. Hal tersebut berdasarkan pada Keputusan Menteri Lingkungan Hidup dan Kehutanan Nomor 07.37.06 Tahun 2015.

Pada Diktum Kedelapan yang menyatakan bahwa penanggung jawab usaha dan atau kegiatan wajib melakukan uji emisi di fasilitas cerobong paling sedikit 1 (satu) kali dalam 6 (enam) bulan yang dilakukan oleh laboratorium terakreditasi dan memenuhi baku mutu emisi udara seperti yang terdapat pada tabel 2 di bawah(KLHK, 2015).

Tabel 2. Parameter Hasil Pengujian dan Baku Mutu Emisi Kegiatan Pemanfaatan Used Oils

\begin{tabular}{|c|c|c|c|}
\hline Parameter & Satuan & Baku Mutu & Hasil Pengujian \\
\hline Partikulat & $\mathrm{mg} / \mathrm{Nm}^{3}$ & 200 & $10-12$ \\
\hline Sulfur Dioksida $\left(\mathrm{SO}_{2}\right)$ & $\mathrm{mg} / \mathrm{Nm}^{3}$ & 700 & $5-6$ \\
\hline Nitrogen Dioksida $\left(\mathrm{NO}_{2}\right)$ & $\mathrm{mg} / \mathrm{Nm}^{3}$ & 700 & $<3$ \\
\hline Hidrogen Fluorida (HF) & $\mathrm{mg} / \mathrm{Nm}^{3}$ & 10 & $<0,03$ \\
\hline Karbon Monoksida (CO) & $\mathrm{mg} / \mathrm{Nm}^{3}$ & 100 & $3-6$ \\
\hline Hidrogen Klorida ( $\mathrm{HCl})$ & $\mathrm{mg} / \mathrm{Nm}^{3}$ & 70 & $<0,03$ \\
\hline Total Hidrokarbon (sebagai $\mathrm{CH}_{4}$ ) & $\mathrm{mg} / \mathrm{Nm}^{3}$ & 35 & $<0,05$ \\
\hline Arsen (As) & $\mathrm{mg} / \mathrm{Nm}^{3}$ & 1 & $<0,001$ \\
\hline Kadmium (Cd) & $\mathrm{mg} / \mathrm{Nm}^{3}$ & 0,2 & $<0,005$ \\
\hline Kromium (Cr) & $\mathrm{mg} / \mathrm{Nm}^{3}$ & 1 & $<0,005$ \\
\hline Timbal (Pb) & $\mathrm{mg} / \mathrm{Nm}^{3}$ & 5 & $<0,01$ \\
\hline Merkuri (Hg) & $\mathrm{mg} / \mathrm{Nm}^{3}$ & 0,2 & $<0,001$ \\
\hline Talium (Tl) & $\mathrm{mg} / \mathrm{Nm}^{3}$ & 0,2 & $<0,02$ \\
\hline
\end{tabular}

Sumber data diolah dari Keputusan Menteri Lingkungan Hidup dan Kehutanan Nomor 07.37.06 Tahun 2015 dan hasil pengukuran dikoreksi terhadap $10 \%$ Oksigen $\left(\mathrm{O}_{2}\right)$ dan pada kondisi normal $\left(25^{\circ} \mathrm{C} ; 760 \mathrm{mmHg}\right)$. 
Sistem pemantauan emisi kontinu atau continuous emission monitoring system (CEMS) diinstal pada cerobong untuk memantau beberapa parameter emisi yang menjadi parameter kunci dalam mengevaluasi kinerja dari efisiensi pembakaran dan filter bag house sebagai bagian dari pengendalian pencemar udara.

Metode pengambilan sampel CEMS yang diterapkan adalah in stack dilution xxtractive (Schwartz dkk, 1994) untuk memantau partikulat (baku mutu $200 \mathrm{mg} / \mathrm{Nm}^{3}$ ), $\mathrm{SO}_{2}$ (baku mutu 700 $\mathrm{mg} / \mathrm{Nm}^{3}$ ), $\mathrm{NO} / \mathrm{NO}_{2} / \mathrm{NO}_{x}$ (baku mutu $700 \mathrm{mg} / \mathrm{Nm}^{3}$ ). Metode dilution extractive dipilih agar sesuai dengan variabel yang dipantau, instrumen yang digunakan, dan kondisi cerobong (PTFI, 2017).

Sistem pengenceran (dilution system) pada metode ini memiliki kelebihan yaitu:

a. laju aliran gas rendah,

b. mengencerkan sampel gas dengan udara kering bersih,

c. meminimalkan perawatan,

d. jalur sampel berbiaya lebih rendah dan tidak dipanaskan, dan

e. mudah dioperasikan.

Komponen sistem pengenceran terdiri atas:

a. probe pengenceran,

b. kontrol probe pengenceran,

c. jalur sampel tidak dipanaskan,

d. penganalisis gas $\left(\mathrm{SO}_{2}, \mathrm{O}_{2}, \mathrm{NO}_{x}, \mathrm{CO}_{2}, \mathrm{CO}\right)$,

e. kalibrator gas, dan

f. subsistem pembersihan udara.

Tipe pengukuran terdiri atas:

a. chemiluminescence untuk $\mathrm{NO}_{\mathrm{x}}$,

b. UltraViolet (UV) Pulsed Fluorescence untuk $\mathrm{SO}_{2}$,

c. Gas Filter Correlation-Infra Red (GFC-IR) untuk $\mathrm{CO}$,

d. Non Dispersive Infra Red (NDIR) untuk $\mathrm{CO}_{2}$ diluent.

Prinsip bekerja probe pengenceran (dilution probe) seperti yang digambarkan pada gambar 8, yaitu melakukan empat fungsi kritis untuk menyiapkan sampel dari cerobong sehingga dapat diukur secara akurat dan tepat oleh penganalisa.

Sistem ini menggunakan aspirator yang digerakkan udara, yang mengekstraksi sampel dari cerobong, kemudian dilewatkan secara berurutan melalui filter partikulat kasar dan halus, gelas kritis atau lubang kritis kuarsa yang telah dipilih dan diencerkan dengan udara dari aspirator.

Proses ini mengurangi titik embun sampel pada cerobong menjadi di bawah udara ambien. Alat ini menyiapkan sampel yang sarat dengan partikel basah yang hangat, sehingga dapat diangkut melalui jalur yang tidak dipanaskan ke alat analisis hingga sejauh 800 kaki (250 meter).

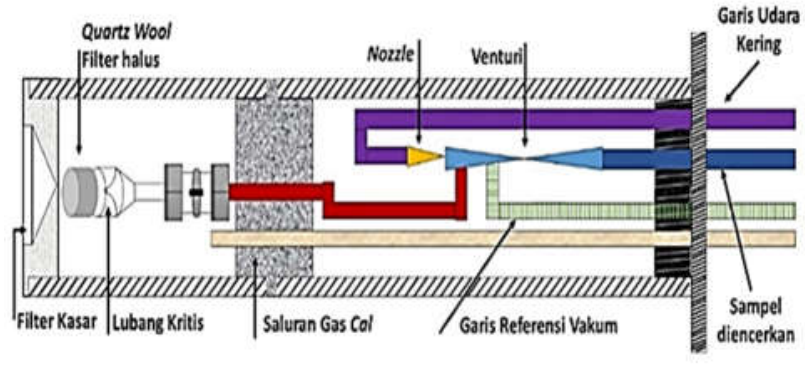

Gambar 8. Dilution Probe

Faktor pengenceran tergantung pada ukuran lubang (orifice) dan laju alir (flow rate). Rasio pengenceran dari sejumlah kecil gas sampel dicampur dengan udara instrumen kering yang bersih digambarkan pada persamaan berikut:

dimana:

$$
D R=\frac{F}{A+F}
$$

DR : rasio pengenceran (dilution ratio)

A : udara pengenceran melalui probe nozzle primer $(\mathrm{L} / \mathrm{m})$

F : gas buang melalui orifice kritis $(\mathrm{mL} / \mathrm{m})$

Rasio pengenceran yang benar dipilih berdasarkan pengetahuan tentang perkiraan kadar air dan gas dari gas buang dan suhu lingkungan minimum. Sistem pembersihan udara pengenceran ini digambarkan pada gambar 9 .

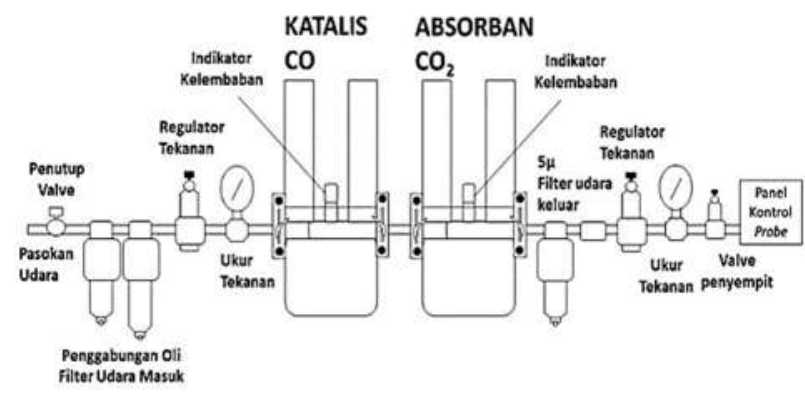

Gambar 9. Sistem Pembersihan Udara Pengencer

Analisis gas emisi menggunakan metode Chemiluminescent $\mathrm{NO} / \mathrm{NO}_{2} / \mathrm{NO}_{\mathrm{x}}$ (Navas dkk, 1998) yang memiliki cara operasi dengan prinsip bahwa nitric oxide (NO) dan ozon $\left(\mathrm{O}_{3}\right)$ bereaksi untuk menghasilkan luminescence yang khas dengan intensitas yang berbanding lurus dengan konsentrasi NO (Jernigen, 2001). Emisi cahaya infra merah dihasilkan ketika molekul $\mathrm{NO}_{2}$ yang tereksitasi secara elektronik meluruh ke tingkat energi yang lebih rendah.

$$
\mathrm{NO}+\mathrm{O}_{3} \rightarrow \mathrm{NO}_{2}+\mathrm{O}_{2}+\mathrm{hv}
$$

Nitrogen dioksida $\left(\mathrm{NO}_{2}\right)$ sebelumnya harus diubah menjadi NO agar dapat diukur menggunakan reaksi chemiluminescent. $\mathrm{NO}_{2}$ dikonversi menjadi $\mathrm{NO}$ oleh konverter molybdenum $\mathrm{NO}_{2}$-ke-NO yang dipanaskan dengan temperatur hingga sekitar $325^{\circ}$ Celcius. Sampel mengalir melalui kapiler dan kemudian ke katup solenoid seperti yang digambarkan pada gambar 10 . 
Katup solenoida mengarahkan sampel langsung ke ruang reaksi (mode NO) atau melalui konverter $\mathrm{NO}_{2}$-ke-NO dan kemudian ke ruang reaksi (mode $\mathrm{NO}_{\mathrm{x}}$ ). Sensor aliran sebelum ruang reaksi mengukur aliran sampel. Udara kering memasuki alat analisis melalui sekat udara kering, melewati saklar aliran, dan kemudian melalui ozonator. Ozonator menghasilkan ozon yang dibutuhkan untuk reaksi chemiluminescence (Grosjean \& Harrison, 1985).

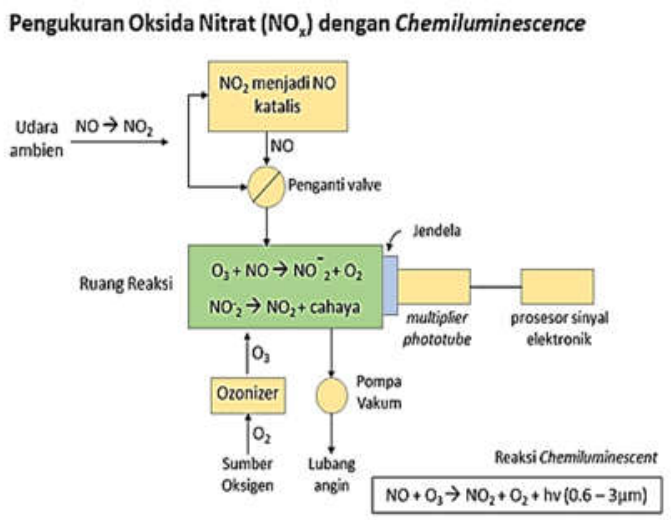

Gambar 10. Chemiluminescent Analyzer

Di ruang reaksi (chamber), ozon bereaksi dengan NO dalam sampel untuk menghasilkan molekul $\mathrm{NO}_{2}$ tereksitasi (Tidona dkk, 1988). Sebuah tabung photomultiplier (PMT) yang ditempatkan di pendingin termoelektrik mendeteksi pendaran yang dihasilkan selama reaksi ini. Dari ruang reaksi, exhaust bergerak melalui konverter ozon $\left(\mathrm{O}_{3}\right)$ ke pompa, dan dilepaskan melalui ventilasi. Konsentrasi $\mathrm{NO}$ dan $\mathrm{NO}_{\mathrm{x}}$ yang dihitung dalam mode $\mathrm{NO}$ dan $\mathrm{NO}_{\mathrm{x}}$ disimpan dalam sebuah unit memori data. Perbedaan antara konsentrasi tersebut yang kemudian digunakan untuk menghitung konsentrasi $\mathrm{NO}_{2}$.

Analisis $\mathrm{SO}_{2}$ dilakukan dengan menggunakan UV Pulsed Fluorescence $\mathrm{SO}_{2}$ Analyzer (Luke, 1997) seperti yang digambarkan pada gambar 11. Prinsip analisis tersebut didasarkan pada sifat dari molekul $\mathrm{SO}_{2}$ yang menyerap sinar UV dan menjadi aktif pada satu panjang gelombang, kemudian meluruh ke keadaan energi yang lebih rendah dengan memancarkan sinar UV pada panjang gelombang yang berbeda. Reaksi tersebut digambarkan seperti di bawah ini (Mohn \& Emmenegger, 2014):

$$
\mathrm{SO}_{2}+h v_{1} \rightarrow \mathrm{SO}_{2}{ }^{*} \rightarrow \mathrm{SO}_{2}+h v_{2}
$$

Sampel mengalir melalui 'kicker' hidrokarbon, yang menghilangkan hidrokarbon dari sampel dengan memaksa molekul hidrokarbon meresap melalui dinding tabung. Molekul $\mathrm{SO}_{2}$ melewati 'kicker' hidrokarbon yang tidak terpengaruh. Sampel kemudian mengalir ke ruang fluoresensi, di mana sinar UV yang berdenyut mengaktifkan molekul $\mathrm{SO}_{2}$. Adapun lensa kondensasi memfokuskan sinar UV yang berdenyut kedalam unit cermin. Rakitan cermin berisi empat cermin selektif yang hanya memantulkan panjang gelombang yang mengaktifkan molekul $\mathrm{SO}_{2}$.

Ketika molekul $\mathrm{SO}_{2}$ tereksitasi meluruh ke keadaan energi lebih rendah, mereka memancarkan sinar UV yang sebanding dengan konsentrasi $\mathrm{SO}_{2}$. Filter bandpass hanya memungkinkan panjang gelombang yang dipancarkan oleh molekul $\mathrm{SO}_{2}$ tereksitasi untuk mencapai tabung PMT. Fungsi PMT yaitu untuk mendeteksi emisi sinar UV dari molekul $\mathrm{SO}_{2}$ yang meluruh.

Photo-detector yang terletak di bagian belakang ruang fluoresensi, terus-menerus memonitor sumber cahaya UV yang berdenyut dan terhubung ke sirkuit yang mengkompensasi fluktuasi dalam cahaya UV tersebut. Sampel meninggalkan ruang optik, dan kemudian melewati sensor aliran, kapiler, dan sisi 'shell' dari 'kicker' hidrokarbon. Sampel kemudian menuju pompa dan terbuang keluar.

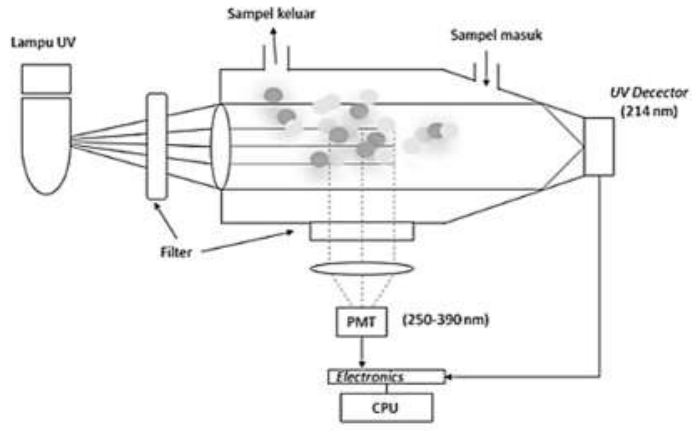

Gambar 11. Fluorescence Analyzers

Prinsip dalam pemantauan partikel seperti yang digambarkan pada gambar 12 yaitu menggunakan laser, dimana partikel pada cerobong diterangi oleh laser. Jumlah cahaya laser yang terpendar kembali dari partikel yang kemudian diukur dengan detektor. Persebaran tersasar dan cahaya sekitar dapat dihilangkan dengan menyetel bidang pandang instrumen dan dengan menggunakan sumber laser termodulasi. Respon instrumen sebanding dengan konsentrasi debu. Kalibrasi dilakukan untuk memberikan pengukuran dalam $\mathrm{mg} / \mathrm{m}^{3}$ untuk kemudian dibandingkan dengan hasil tes referensi standar yaitu tes isokinetic (USEPA, 2017; USEPA 2019).

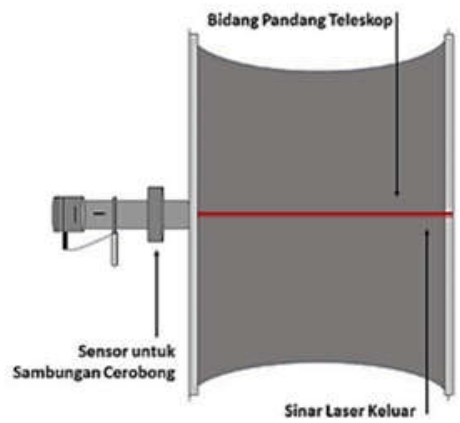

Gambar 12. Prinsip Kerja Pemantauan Emisi Partikulat

Data hasil pemantauan CEMS untuk parameter partikulat, $\mathrm{SO}_{2}$ dan $\mathrm{NO}_{\mathrm{x}}$ seperti yang terlihat pada tabel 2. Hasil menunjukkan bahwa emisi sangat jauh di bawah nilai baku mutu yang dipersyaratkan dalam perizinan. Hal tersebut dipengaruhi oleh used oils dengan kadar kontaminan yang terkandung telah memenuhi syarat kualitas seperti tertera pada tabel 1 , 
di mana selain parameter logam berat, titik nyala dan nilai kalori, nilai kandungan air dan TOX pun memenuhi baku mutu. Selain kualitas LB3 yang digunakan, proses preheating, mixing dan blending, pembakaran di tanur bakar berputar, serta efisiensi teknologi yang digunakan untuk PPU juga berpengaruh terhadap emisi.

Hasil pengujian parameter emisi tertera pada tabel 2. Nilai parameter $\mathrm{NO}_{\mathrm{x}}, \mathrm{SO}_{\mathrm{x}}, \mathrm{CO}$ dan partikulat memenuhi baku mutu yang ditetapkan pada perizinan. Pelaksanaan pemantauan emisi dengan metode manual yaitu dengan metode isokinetik tetap dilakukan sebagai pembanding bahwa hasil pemantauan CEMS tidak memiliki perbedaan yang sangat tinggi. Selain itu, hasil pengukuran dengan isokinetik tersebut tetap diperlukan untuk memperoleh kadar dari parameter $\mathrm{HF}, \mathrm{HCl}$, total hidrokarbon sebagai $\mathrm{CH}_{4}$ dan logam berat (KLHK, 2015).

\section{Kesimpulan}

Pemanfaatan LB3 yaitu minyak pelumas bekas (used oils) untuk digunakan sebagai bahan subtitusi bahan bakar untuk produksi kapur tohor di pabrik pengolahan kapur Mahaka PTFI telah memenuhi persyaratan dari peraturan perizinan yang ditentukan oleh pemerintah RI.

Sebagai upaya mengelola kualitas emisi dari pabrik pengolahan kapur tohor agar memenuhi standar kualitas yang ditentukan, maka diperlukan sejumlah tindakan dan pengelolaan lain seperti melakukan pemeliharaan rutin pada perangkat dan peralatan pengendalian polusi seperti bag filter pada baghouse, pemeliharaan ID fan, mengendalikan tekanan udara dan debit campuran antara used oils dan bahan bakar yang berpengaruh langsung pada kualitas emisi, serta melakukan pemantauan internal terhadap emisi gas buang dengan CEMS.

\section{DAFTAR PUSTAKA}

Badan Pengendalian Dampak Lingkungan (BAPEDAL). 1996. Keputusan Kepala Badan Pengendalian Dampak Lingkungan Nomor: Kep-205/BAPEDAL/07/1996 tentang Pedoman Teknis Pengendalian Pencemaran Udara Sumber Tidak Bergerak.

Badan Pengendalian Dampak Lingkungan (BAPEDAL). 1995. Keputusan Kepala Badan Pengendalian Dampak Lingkungan Nomor: Kep-03/BAPEDAL/09/1995 tentang Persyaratan Teknis Pengolahan Limbah Bahan Berbahaya dan Beracun.

Grosjean, D., \& Harrison, J. 1985. Response of chemiluminescence NOx analyzers and ultraviolet ozone analyzers to organic air pollutants. Environmental Science \& Technology, 19 (9): 862-865. https://doi.org/10.1021/es00139a016

International Council on Mining and Metals. 2020. 10 principles.

https://www.icmm.com/website/publications/pdfs/ mining-principles/mining-principles.pdf

Jernigan, J.R. 2001. Chemiluminescence NOx and GFC NDIR CO Analyzers for Low Level Source Monitoring.
Thermo Environmental Instruments. http://citeseerx.ist.psu.edu/viewdoc/download?doi= 10.1.1.148.1975\&rep=rep1\&type=pdf

Kementerian Lingkungan Hidup (KLH). 2008. Peraturan Menteri Negara Lingkungan Hidup Nomor 02 Tahun 2008 tentang Pemanfaatan Limbah Bahan Berbahaya dan Beracun.

Kementerian Lingkungan Hidup dan Kehutanan (KLHK). 2015. Peraturan Menteri Lingkungan Hidup dan Kehutanan Nomor 07.03.06 Tahun 2015 tentang Izin Pengelolaan Limbah Bahan Berbahaya dan Beracun Untuk Kegiatan Pemanfaatan Limbah Bahan Berbahaya dan Beracun PT Freeport Indonesia.

Kementerian Lingkungan Hidup dan Kehutanan (KLHK). 2020a. Peraturan Menteri Lingkungan Hidup dan Kehutanan Republik Indonesia Nomor P.10/MENLHK/SETJEN/PLB.3/4/2020 tentang Tata Cara Uji Karakteristik dan Penetapan Status Limbah Bahan Berbahaya dan Beracun.

Kementerian Lingkungan Hidup dan Kehutanan (KLHK). 2020b. Peraturan Menteri Lingkungan Hidup dan Kehutanan Republik Indonesia Nomor P.12/MENLHK/SETJEN/PLB.3/5/2020 tentang Penyimpanan Limbah Bahan Berbahaya dan Beracun.

Kementerian Negara Lingkungan Hidup (KLH). 2014. Peraturan Menteri Lingkungan Hidup Nomor 4 Tahun 2014 tentang Baku Mutu Emisi Sumber Tidak Bergerak Bagi Usaha Dan/Atau Kegiatan Pertambangan.

Kementerian Negara Lingkungan Hidup (KLH). Peraturan Menteri Lingkungan Hidup Nomor 14 Tahun 2013 tentang Simbol dan Label Limbah Bahan Berbahaya dan Beracun.

Kementerian Negara Lingkungan Hidup (KLH). Peraturan Menteri Negara Lingkungan Hidup Nomor 18 Tahun 2009 tentang Tata Cara Perizinan Pengelolaan Limbah Bahan Berbahaya dan Beracun.

López-Vazquez, C.M., Fall, C. 2004. Improvement of a Gravity Oil Separator Using a Designed Experiment. Water, Air, \& Soil Pollution, 157, 33-52. https://doi.org/10.1023/B:WATE.0000038874.8541 3.05

Luke, W.T. 1997. Evaluation of a commercial pulsed fluorescence detector for the measurement of lowlevel concentrations during the Gas-Phase Sulfur Intercomparison Experiment. Journal of Geophysical

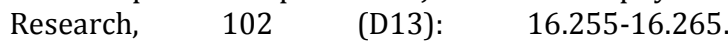
https://agupubs.onlinelibrary.wiley.com/doi/epdf/1 $0.1029 / 96 J D 03347$

Mohn, J., Emmenegger, L. 2014. Determination of Sulphur Dioxide by Pulsed UV-Fluorescence. Environmental Technology, 76: 1-11. https://pdfs.semanticscholar.org/d79e/ef2082b1ffcf 3fd074e079cddbae10f447ed.pdf

Navas, M.J., Jiménez, A.M., Galán, G. Air analysis: determination of nitrogen compounds by chemiluminescence. Atmospheric Environment, 31 (21): 3603-3608. https://doi.org/10.1016/S13522310(97)00153-2

Pemerintah Indonesia (PI). 2014. Peraturan Pemerintah Nomor 101 Tahun 2014 tentang Pengelolaan Limbah 
Bahan Berbahaya dan Beracun. Lembaran Negara RI Tahun 2014 No. 333, Tambahan Lembaran Negara RI No. 5617. Jakarta: Sekretariat Negara.

Pemerintah Indonesia. 2009. Undang Undang Nomor 32 Tahun 2009 tentang Perlindungan dan Pengelolaan Lingkungan Hidup (PPL). Lembaran Negara RI Tahun 2009 No. 140, Tambahan Lembaran Negara RI No. 5059. Jakarta: Sekretariat Negara.

Pemerintah Indonesia. 2012. Peraturan Pemerintah Nomor 27 Tahun 2012 tentang Izin Lingkungan. Lembaran Negara RI Tahun 2012 No. 48, Tambahan Lembaran Negara RI No. 5285. Jakarta: Sekretariat Negara.

PT Freeport Indonesia (PTFI). 2017. Technical Paper: Continuous Emission Monitoring System (CEMS), Concentrating Division. Tembagapura. (Unpublished).

PT Freeport Indonesia (PTFI). 2019. Laporan Pelaksanaan Pengelolaan dan Pemantauan Lingkungan Tahun 2019. Jakarta. (Unpblished).

Schwartz, J., Sample, S., Mcllvaine, R. 1994. Continuous Emission Monitors - Issues and Predictions, Air \& Waste, $\quad 44 \quad$ (1): 16-20. https://doi.org/10.1080/1073161X.1994.10467233

Sugiyono. 2011. Metode Penelitian Pendidikan (Pendekatan Kuantitatif, Kualitatif, dan R\&D). Alfabeta. Bandung.

Susanto, A., Wulan, R.N., Putro, E.K. 2016. Used Oil Utilization for Lime Production as Hazardous Waste Minimization. International Journal of Waste $\begin{array}{llll}\text { Resources, } & 6 & \text { (4): }\end{array}$ https://www.longdom.org/open-access/used-oilutilization-for-lime-production-as-hazardouswasteminimization-2252-5211-1000252.pdf

Tidona, R.J., Nizami, A.A., Cernansky, N.P. 1988. Reducing Interference Effects in the Chemiluminescent Measurement of Nitric Oxides from Combustion Systems. JAPCA, 38 (6): 806-811, https://doi.org/10.1080/08940630.1988.10466421

U.S. EPA. 2017. Method 17 - determination of particulate matter emissions from stationary sources. https://www.epa.gov/sites/production/files/201708/documents/method_17.pdf

U.S. EPA. 2019. Method 5-determination of particulate matter emissions from stationary sources. https://www.epa.gov/sites/production/files/201908/documents/method_5_0.pdf

United States Environmental Protection Agency (USEPA). 2020a. Greenhouse Gas Emissions. https://www.epa.gov/ghgemissions/overviewgreenhouse-gases

United States Environmental Protection Agency (USEPA). 2020b. Greenhouse Gas Emissions. https://www.epa.gov/emc/emc-continuousemission-monitoring-systems

World Health Organization (WHO). 2020. Ambient Air Pollution: Health Impacts. https://www.who.int/airpollution/ambient/healthimpacts/en/ 